TRANSISTORS APPLIED 


\title{
TRANSISTORS APPLIED
}

\author{
H. E. KADEN
}

1965

Macmillan Education 
Translated from the German by E. Grubba, F.I.L. (Eng.), West Monkseaton, England

This book contains $x+194$ pages and 128 illustrations.

Other editions of this book in Philips Technical Library in the German, French and

Spanish language

U.D.C. No. 621.382 .3

\section{ISBN 978-1-349-81806-8 ISBN 978-1-349-81804-4(eBook)}

DOI 10.1007/978-1-349-81804-4

Original German edition:

(C) N.V. Philips' Gloeilampenfabrieken, Eindhoven, The Netherlands, 1963

English edition:

(C) N.V. Philips' Gloeilampenfabrieken, Eindhoven, The Netherlands, 1965

All rights reserved

Softcover reprint of the hardcover 1st edition 1965 978-0-333-00199-8

No representation or warranty is given that the matter treated in this book is free from patent rights; nothing herein should be interpreted as granting, by implication or otherwise, a licence under any patent rights. 


\section{PREFACE}

The transistor is being used nowadays as a technical amplifying element in almost every field of technology. In consequence, the valve is more and more superseded by the transistor. To the same extent as the transistor is replacing the valve, those who up to now have only worked with valves must now also become familiar with transistors. Experience has shown that the amplifying element "valve" is theoretically relatively easily mastered by students, apprentices, amateur technicians and so on. Why is it then that those very circles who successfully apply the theoretical knowledge concerning the operation of the valve in the circuit show an aversion to assimilating the theoretical fundamentals of the transistor? Is the operation of a transistor as an amplifying element really so different in principle compared with the valve? Is it necessary to replace the simple formulae of the valve by obscure four-pole equations in the case of the transistor? The answer to that is an emphatic "No!". The transistor is just as easy to understand as an amplifying element in the circuit as the valve. Granted, the internal physics of the transistor present more difficulty than with the valve. This, however, is by no means simple in the valve and what "expert" in the use of the valve has hitherto bothered himself about the internal more profound physical processes of the valve? It is important for the user of valves and transistors to know what this type of amplifier can do. Here the greatest interest lies in the characteristic values and curves. This does not mean that one should know nothing at all about the internal physical processes in a transistor. It ought to be said, however, that over-emphasis on the physical processes in the transistor has "soured" its theoretical presentation to a large extent.

This text-book contains a short essential treatise on the physical facts necessary to explain certain specific transistor properties. Its chief aim, however, is the presentation of the principles of the transistor as an amplifying element in combination with the essential circuit elements. Here we are not so much concerned with reproducing the greatest possible number of circuits built up as with arousing a basic knowledge of which suitable chosen circuits to understand and eventually to develop oneself. Pure algebra is the only mathematical science required to study this book. In order that the less experienced may be able to concentrate on transistor problems, the 
most important properties of the transistor compared with those of the valve have been set out in the form of an introduction. This summary may serve the more skilled reader as a quick survey. The detailed explanations mainly cover the so-called small signal amplification at low and high frequencies. The derivations are included in such a way that even those who dislike the formulae will be able to follow them without difficulty. Numerical examples given after each problem should consolidate the material and give the feeling for magnitude and dimensions.

The presentation of the transistor has been carried out in exactly the same way as that which has already become classical for the valve. It is therefore to be hoped that as a result of the uniformity of the presentation a better and clearer connection will be shown between the two amplifying elements and with it a basis for easier comprehension of the transistor. 


\section{CONTENTS}

PREFACE.................

CHAPTER 1 INTRODUCTION . . . . . . . . . . . . 1

1.1. The transistor versus the tube . . . . . . . . . 1

1.2. The fundamental circuit of the transistor and the electron tube ................ 1

1.3. Why does the transistor amplify? . . . . . . . 1

1.4. Why does the electron tube amplify? . . . . . . . 2

1.5. How strongly does an electron tube amplify? . . . . . 3

1.6. How much does a transistor amplify?. . . . . . . . . 7

1.7. What simple circuit illustrates amplification in the electron tube? . . . . . . . . . . . . 13

1.8. What simple circuit illustrates amplification in the transistor? . . . . . . . . . . . . . . 14

1.9. How is the working point set? . . . . . . . . 15

1.10. What is the effect of feedback? . . . . . . . . 16

1.11. What is the residual current? . . . . . . . . 19

1.12. How does temperature affect the transistor? . . . . . 19

1.13. What is "stabilisation"? . . . . . . . . . 20

1.14. What peculiarities have the cathode follower and the common collector circuit?. . . . . . . . . . . . 20

1.15. Are the earthed grid stage and the common base stage equal to each other? . . . . . . . . . . . . 21

1.16. A word about current and voltage directions . . . . 22

CHAPTER 2 PHYSICAL PRINCIPLES OF THE TRANSISTOR 24

2.1. The conduction mechanism in germanium. . . . . . 24

2.1.1. Crystal structure . . . . . . . . . . . . 24

2.1.2. Intrinsic conduction . . . . . . . . . . 24

2.1.3. Extrinsic conduction . . . . . . . 25

2.2. The $p-n$ boundary layer . . . . . . . . . 27

2.3. The $p$-n-combination as rectifier . . . . . . . . 29

2.4. The junction transistor . . . . . . . . . 30 
VIII

CONTENTS

CHAPTER 3 SYMBOLS, SIGNS, FUNDAMENTAL CIRCUIT

CHAPTER 4 THE FOUR QUADRANT CHARACTERISTIC FIELD . . . . . . . . . . . 34

CHAPTER 5 TWO-POLE REPRESENTATION OF THE TRANSISTOR ............ . . 39

CHAPTER 6 TRANSISTOR EQUIVALENT CIRCUIT. . . . 46

6.1. Voltage equivalent circuit . . . . . . . . . . 46

6.2. Current equivalent circuit . . . . . . . . . . 46

CHAPTER 7 FIXING THE OPERATING POINT . . . . . 48

7.1. Fixing with series resistance . . . . . . . . . . 48

7.2. Adjustment with low resistance voltage divider . . . . 49

CHAPTER 8 APPARENT INTERNAL RESISTANCE WITH LOAD VARIATION .......... 52

CHAPTER 9 TRANSISTORS WITH NEGATIVE FEEDBACK . 58

9.1. Series feedback . . . . . . . . . . . . 59

9.1.1. Voltage control; influence of the control generator 66

9.1.2. The apparent transistor characteristic values with series feedback . . . . . . . . 70

9.2. Parallel feedback . . . . . . . . . . . . . . 72

9.2.1. Current control; influence of the control generator 77

9.2.2. The apparent characteristic values of the transistor with parallel feedback . . . . . . . . 80

9.3. Stabilisation characteristic value . . . . . . . . 83

9.4. Non-linear distortions . . . . . . . . . . . 85

9.4.1. The non-linear distortion factor . . . . . . . 85

9.4.2. Improving the non-linear distortion factor . . . 86

9.5. Working point stabilisation . . . . . . . . 88

CHAPTER 10 THE INFLUENCE OF TEMPERATURE ON THE TRANSISTOR. ........... 92

10.1. Permissible transistor dissipation. . . . . . . . . 92

10.2. Temperature influence on the collector current . . . . 94 
10.2.1. Constant d.c. base and collector voltage . . . . 96

10.2.2. Load resistance . . . . . . . . . . . . . . . 99

10.2.3. Temperature stabilisation by means of feedback . 101

10.2.4. Temperature compensation with thermistors . . 102

10.2.5. Stabilisation by a base series resistance. . . . . 103

CHAPTER 11 TRANSISTOR LEAKAGE CURRENTS . . . . 104

11.1. Unstabilised circuit . . . . . . . . . . . . . 105

11.2. Leakage current influence with stabilised constant base current . . . . . . . . . . . . . . . 105

11.3. The leakage current influence with stabilisation of the emitter current . . . . . . . . . . . 107

11.4. Leakage current influence with stabilisation of the collector current . . . . . . . . . . . . 110

CHAPTER 12 DIRECT CURRENT AMPLIFICATION . . . 114

12.1. Emitter circuit . . . . . . . . . . . . 114

12.2. Base circuit . . . . . . . . . . . . 115

CHAPTER 13 CHARACTERISTIC VALUES AND THEIR DEPENDENCE UPON THE WORKING POINT . . 116

13.1. The transistor as regulating device . . . . . . . . 118

CHAPTER 14 THE COMMON COLLECTOR CIRCUIT . . . . 121

14.1. The equivalent characteristic values of the common collector stage. . . . . . . . . . . . 127

CHAPTER 15 THE COMMON BASE CIRCUIT . . . . . 130

15.1. The equivalent characteristic values of the common base stage . . . . . . . . . . . . 134

CHAPTER 16 HIGH FREQUENCY BEHAVIOUR OF THE TRANSISTOR. . . . . . . . . . 136

16.1. Transistor capacitances . . . . . . . . . . 136

16.1.1. Barrier layer capacitance $C_{r}$. . . . . . . 136

16.1.2. Diffusion capacitance $C_{i}$. . . . . . . . . . . 137

16.1.3. The output capacitance $C_{0}$. . . . . . . . . 139 
16.2. The high frequency equivalent circuit diagram . . . . 139

16.3. Limiting frequencies . . . . . . . . . . . . 141

16.3.1. The limiting frequency of short-circuit current amplification . . . . . . . . . 142

16.3.2. The upper limiting frequency of voltage amplification in the common emitter circuit . . . . . 151

16.3.3. The upper limiting frequency of voltage amplification in the common base circuit . . . . . 152

CHAPTER 17 MULTISTAGE LF AMPLIFIERS . . . . . 158

17.1. RC amplifier . . . . . . . . . . 158

17.1.1. Upper limiting frequency . . . . . . . . 159

17.1.2. Lower limiting frequency. . . . . . . . . . . 160

17.1.3. The emitter capacitance $C_{E}$. . . . . . . 162

17.2. Transformer coupling . . . . . . . . . 165

17.2.1. Current control . . . . . . . . . 166

17.2.2. Output matching . . . . . . . . 166

CHAPTER 18 RESONANCE AMPLIFIER . . . . . . . 168

18.1. Neutralisation . . . . . . . . . . . . 171

18.2. Bandfilter coupling . . . . . . . . . . 171

CHAPTER 19 AMPLIFIER NOISE. . . . . . . . 175

19.1. Resistance noise . . . . . . . . . . . . . 175

19.2. Transistor noise . . . . . . . . . . . . 178

CHAPTER 20 SUMMARY OF COMPARISONS BETWEEN THE TRANSISTOR AND ELECTRON TUBE . . . . 183

20.1. Formula and circuit comparison . . . . . . . . 184 Symbols . . . . . . . . . . . . . . . . . 190

Bibliography .................... 191

Index . . . . . . . . . . . . . . . . 193 